\title{
A teoria de P. Ya. Galperin e a formação de conceitos teóricos na educação em Ciências. Reflexões críticas e possibilidades
}

\author{
The theory of P. Ya's Galperin and the formation of theoretical \\ concepts in science education. Critical reflections and possibilities
}

\author{
Isauro Beltrán Núñez ${ }^{1}$ \\ Betânia Leite Ramalho ${ }^{2}$ \\ Marcus Vinicius de Faria Oliveira ${ }^{3}$
}

\begin{abstract}
RESUMO
Este artigo sintetiza reflexões sobre o processo de formação de conceitos teóricos na educação em Ciências baseada na teoria de P. Ya. Galperin. Tomamos como contexto algumas críticas tradicionalmente feitas à teoria, reforçadas (embora não intencionalmente) em estudos atuais de pesquisas no contexto brasileiro que abordam esse processo. Partimos da natureza lógica dialética dos conceitos teóricos e do papel de sua definição para justificar a formação da base orientadora do tipo III como mecanismo psicológico da aprendizagem desses conceitos. $\mathrm{Na}$ discussão, pretendemos oferecer um ponto de vista que se contrapõe com posturas teóricas que consideramos interpretações parciais ou malentendidos das ideias de Galperin, sempre reconhecendo suas limitações, próprias de qualquer teoria científica.
\end{abstract}

Palavras-chave: Formação de conceitos teóricos. Teoria de Galperin. Críticas. Educação em Ciências.

\begin{abstract}
This article synthesizes reflections on the process of forming theoretical concepts in science education based on P. Ya. Galperin's theory. We take as context some criticisms traditionally made to the theory, reinforced (although not intentionally) in current research studies in the Brazilian context that address this process. We start from the logical dialectical nature of theoretical concepts and the role of their definition to justify the formation of the type III as a psychological learning mechanism of these concepts. In the discussion, we intend to offer a point of view that is opposed to theoretical positions that we consider partial interpretations or misunderstandings of Galperin's ideas, always recognizing their limitations, typical of any scientific theory.
\end{abstract}

Keywords: Formation of theoretical concepts. Galperins theory. Criticas. Science education.

\footnotetext{
1 Professor titular do Centro de Educação - UFRN. ORCID: https://orcid.org/0000-0003-32244694. E-mail: isaurobeltran@yahoo.com.br.

2 Professora titular do Centro de Educação - UFRN. ORCID: https://orcid.org/0000-0003-01392416. E-mail: betania.ramarlho@gmail.com.

${ }^{3}$ Professor do Instituto Federal de Educação, Ciência e Tecnologia do Rio Grande do Norte IFRN. ORCID: https://orcid.org/0000-0002-2734-0633. E-mail: marcus.oliveira@ifrn.edu.br.
} 


\section{Introdução}

$\mathrm{Na}$ área da educação em Ciências no Brasil, a formação de conceitos científicos no contexto escolar é uma temática de grande relevância para a educação científica dos estudantes. Essa importância se revela nos números significativos de estudos, e de maneira expressiva naqueles que estão referenciados na Teoria Histórico Cultural de L. S. Vigotsky e seus discípulos, como V. V. Davidov, N. F. Talizina e P. Ya. Galperin

Nossa familiarização com muitos desses estudos, vários publicados em revistas e anais de eventos científicos, mostram uma diversidade de interpretações e formas de organização didática dos processos de ensino de conceitos científicos baseados na teoria de Galperin, o que consideramos ser de grande relevância. No entanto, constatamos que resultados de pesquisas, especialmente nos níveis de mestrado e doutorado, apresentam uma simplificação das ideias da teoria de Galperin, bastante relacionada com críticas que tradicionalmente são feitas à teoria. Ao se referirem a essas críticas, autores como Liders et al. (2012), Núñez (2009), Sidneva (2019), entre outros, as consideram inadequadas e resultado de interpretações reducionistas, por vezes, incoerentes, que não levam em conta os pressupostos filosóficos, epistemológicos e da própria dinâmica e historicidade das ideias de Galperin, segundo destaca Gabay (2012).

Com base no problema exposto, nos interessa, neste artigo, discutir a compreensão que temos da formação de conceitos científicos no contexto da educação em Ciências, baseada na Teoria de Formação Planejada das Ações Mentais e dos Conceitos de P. Ya. Galperin. Daremos ênfase em alguns tópicos das críticas à teoria que consideramos relevante e, por vezes, negligenciada em pesquisas que assumem segui-la para a formação de conceitos em Ciências.

A discussão se baseia nas interpretações que temos realizado há mais de 20 anos, avaliando trabalhos nas bancas de dissertações e teses, na avaliação de artigos e projetos como pareceristas ad hoc, nas discussões em eventos acadêmicos, entre outros. Temos nos confrontado com limitações e potencialidades dos nossos conhecimentos da teoria e da busca de uma 
compreensão do seu potencial heurístico, como marco teórico, no qual se integram de forma dialética as ideias de L. S. Vigotsky, A. N. Leontiev, P. Ya. Galperin e alguns dos discípulos desse último como N. F. Talizina e V.V. Davidov. Esta discussão não pretende unificar ou silenciar outros pontos de vistas, mas contribuir com o enriquecimento de interpretações conferidas ao caráter dialético, flexível, aberto e heurístico das ideias de Galperin como uma teoria científica.

Para esse propósito, organizamos o texto da seguinte forma: a) uma discussão sobre o que entendemos serem esses conceitos na teoria de Galperin, uma vez que desse conhecimento depende a compreensão acerca do lugar que ocupa a definição de conceitos como procedimentos lógicos no processo da sua formação; b) os fundamentos e o caráter sistêmico, complexo e dialético da teoria de Galperin, o que nos leva a uma reflexão sobre os subsistemas da teoria e a importância de pensá-la de forma integral quando assumimos a formação da base orientadora tipo III como mecanismo psicológico da formação dos conceitos teóricos. Desejamos apontar que, se essa situação for desconsiderada em razão de leituras fragmentadas e estereotipadas das ideias de Galperin, florescerão equívocos e críticas a respeito dessas ideias.

\section{Os conceitos sob a perspectiva da teoria de Galprin e sua definição na lógica}

Dentre as críticas que fazem à teoria de Galperin, alguns pesquisadores, como assinala Sidneva (2019),-se referem ao fato de esta não explicar a aprendizagem de todos os tipos de conceitos. Entendemos que essas críticas ignoram o fato da teoria se referir a conceitos sob o ponto de vista da lógica dialética. No caso da educação em Ciências, trata de conceitos teóricos estruturantes das disciplinas científicas (Química, Física, Biologia) cuja formação demanda influências pedagógicas distintas das formas como se aprendem os conceitos do cotidiano ou os conceitos cientificos, no sentido de Vigotsky (1987). São conceitos que, como generalizações teóricas, revelam as características e relações essenciais de uma classe de objetos segundo a lógica 
dialética num dado campo disciplinar, às quais os estudantes geralmente não têm acesso fora do contexto escolar.

$\mathrm{Na}$ teoria de Galperin (2001a), podemos considerar a ideia do conceito teórico como forma de atividade mental por intermédio da qual se reproduz o objeto real na forma de objeto ideal e seu sistema de relações que refletem a universalidade ou a essência do movimento dialético do objeto real em sua unidade. É importante ressaltar que, nesse caso, não se trata de um objeto singular, mas de uma classe de objetos que compartilham características essenciais.

Os conceitos teóricos são estruturas básicas do conhecimento racional. Nas Ciências, aparecem como uma das formas de refletir o mundo na consciência, e ajudar a conhecer a essência de uma classe de objetos, fatos ou fenômenos, ao abstrair e generalizar seus aspectos mais significativos e essenciais no campo científico. Um conceito teórico tem um caráter aproximado, que nele se reflete de acordo com a ciência, de forma ativa e adequada à realidade, mas não se trata de um reflexo mecânico no qual se estabelecem relações de identidade entre a realidade e representação ou realidade e imagem.

Nessa perspectiva, reafirmamos que o conceito não pode ser reduzido à soma de vínculos empíricos associativos formados pela memória, uma vez que é um autêntico ato do pensamento. Por isso, sua formação pressupõe o desenvolvimento de várias funções intelectuais, tais como atenção, memoria lógica, abstração, comparação, diferenciação, generalização, dentre outras. Compreender um conceito é um ato de apropriação significante.

Segundo a lógica, o conteúdo da extensão ou o volume podem ser diferenciados nos conceitos. O primeiro diz respeito ao conjunto de características essenciais que definem a classe dada, o segundo se expressa no número de objetos que se relacionam e nele se incluem. Por sua vez, é importante conhecer a estrutura lógica do conceito, determinada pelas formas como se relacionam as caracteísticas essenciais da classe por ele representada. Nesse sentido, os conceitos podem ter estrutura conjuntiva (as propriedades essências se unem pela conjunção "e") estrutura disjuntiva (as propriedades essenciais se unem pela disjunção "ou") ou estrutura conjuntiva-disjuntiva (as relações se unem por conjunções e disjunções). 
Compartilhamos com Talízina (2009) a ideia de que, em princípio, é impossível imaginar um conceito teórico de maneira concreta. Qualquer representação constitui uma imagem de um objeto concreto, mas a referida imagem necessariamente terá algumas características irrelevantes. Sendo assim, o conceito teórico não pode ser uma imagem sensorial concreta e, sim, a imagem abstrata que funciona no pensamento em estreita relação com as palavras e a linguagem, como uma imagem generalizada que tem em si as características essenciais de toda uma classe de objetos e não as características de algum objeto isolado. É certo que, se consideramos a dialética do geral e do singular, o geral só existe no singular, da mesma forma é assim para o abstrato que só existe no concreto. Por isso, embora a representação seja uma abstração, traz consigo todo o singular da classe que representa.

$\mathrm{Na}$ nossa interpretação da teoria de Galperin, os conceitos a serem formados na educação científica, segundo uma orientação do terceiro tipo, são conceitos teóricos, que constituem os núcleos estruturantes do conteúdo da disciplina científica e são, por sua vez, susceptíveis à definição segundo a lógica dialética. Por isso, a importância desse procedimento do pensamento na formação dos conceitos teóricos das Ciências.

A aplicação ou não da teoria de Galperin em determinadas disciplinas do currículo escolar também pode estar relacionada com a tradição dessas disciplinas em se organizar segundo os conceitos teóricos estruturantes do campo disciplinar. Ainda há a necessidade de trabalhar o ensino desses conceitos na forma da lógica dialética o que supõe sua definição precisa, ou seja, o estabelecimento de seu conteúdo e estrutura lógica. Atenta-se, assim, para o processo de sua formação que exige o uso consciente, reflexivo e sob o controle deliberado dos estudantes do conteúdo do conceito na solução de situaçõesproblema, processo necessário ao desenvolvimento das funções psicológicas superiores e, consequentemente, do pensamento científico dos estudantes.

A definição de conceitos é um processo de categorização da realidade que, nas Ciências Naturais, permite organizar os objetos em classes e dar sentido à referida classe, diferenciando-a de outras, o que é fundamental na produção do 
conhecimento científico, necessário à comunicação científica de novos conhecimentos que se expressam na forma de conceitos científicos

A definição como procedimento lógico revela o conteúdo do conceito, ou seja, a intenção, que diz respeito às características essenciais dos objetos ou fenômenos de uma dada classe que nela se refletem. Esse conteúdo passa a ser parte da base orientadora, na qual se também incluem as ações que se devem realizar nos processos de solução das tarefas.

Inicialmente, os estudantes não precisam memorizar o conteúdo do conceito. Eles o aprendem na medida que o usam e se orientam utilizando-o na solução das tarefas práticas devidamente contextualizadas e planejadas pelo professor. Note-se que, dessa forma, não se separa o momento de aprender o conceito teórico de sua aplicação.

$\mathrm{Na}$ linha de pensamento exposta anteriormente, se evidencia a importância da clareza da natureza dos conceitos teóricos como estruturas do pensamento lógico e do papel da sua definição nos processos de sua formação na educação em Ciências, segundo a teoria de Galperin. Dessa forma, a interpretação que se desenvolve neste artigo é válida para a formação desse tipo de conceitos nas aulas de Ciências, o que também pode ser válido para outras disciplinas em relação a esse tipo de conceitos do conteúdo escolar.

\section{A aprendizagem (formação) de conceitos teóricos na Teoria de P. Ya. Galperin}

Partimos de uma reflexão do que interpretamos como aprendizagem de conceitos teóricos na teoria de Galperin, aplicada ao contexto da educação em Ciências na educação básica, assim como sua finalidade que é o desenvolvimento intelectual e consequentemente da personalidade do estudante. Por sua vez, como uma forma de responder a críticas centradas na ideia da teoria de Galperin ser o fundamento de numa tecnologia de ensino linear que não favorece o desenvolvimento dos estudantes, destacamos a unidade dialética entre ensino e aprendizagem que se tornam inseparáveis no processo, 
É reiterativa, a afirmação, presente em muitos estudos, da definição da aprendizagem de Galperin (2001b) referida como um processo da formação de novas habilidades e conhecimentos ou de sua atualização. Essa reiteração nos leva a duas observações: a) a falta da relação entre aprendizagem, ensino e desenvolvimento que decorrem de leituras superficiais de ideias de Galperin, que conceituam a aprendizagem dos conceitos relacionados ao ensino, configurados como uma unidade dialética, que, no idioma russo, se denomina obuchénie. Consequentemente, ao se falar na teoria do ensino ou da aprendizagem, se faz referência ao termo obuchénie no sentido da indissociabilidade desses dois processos. E b) o ocultamento da essência do termo obuchénie que se encontra na elaboração ou reelaboração da ação de orientação necessária às referidas habilidades e conceitos, que passa a ser um componente da atividade mental que guia a execução, regulação e controle da atividade da personalidade segundo determinado objetivo.

De fato, ao assumir-se relações dialéticas entre ensino, aprendizagem e desenvolvimento da personalidade, deve-se pensar no significado dessa relação, algo que também está praticamente ausente em muitos dos estudos de formação de conceitos teóricos baseados na teoria de Galperin. Isso significa atender às exigências filosóficas que embasam a teoria (NÚÑEZ; OLIVEIRA, 2015), e, no processo de ensino-aprendizagem, encontrar as contradições que geram o desenvolvimento intelectual e da personalidade dos estudantes como forças motrizes. Situações-problemas têm sido utilizadas em discussões sobre a motivação inicial como fontes de conflitos geradores de necessidades para a aprendizagem, como aponta Núñez e Ramalho (2017), sem que se tenha avançado no sentido mais amplo do pensamento dialético do professor, que permita compreender como manter e fortalecer a motivação dos estudantes baseada nas contradições dialéticas inerentes ao processo de ensino e aprendizagem.

Para Galperin (2001a), a aprendizagem é uma atividade que resulta na formação de novos conceitos científicos e habilidades para aqueles que aprendem, ou a incorporação de novas qualidades aos que já a possuem, para os quais se deve elaborar (ou reelaborar) uma ação de orientação adequada para formar a habilidade e / ou assimilação de conhecimentos. Mas essa aprendizagem resulta 
de um ensino devidamente organizado, que potencializa o desenvolvimento intelectual e, consequentemente, da personalidade dos estudantes.

Galperin (2001a) demonstra com clareza que a aprendizagem de conceitos teóricos se concretiza quando o estudante elabora ou reelabora uma base orientadora geral como modelo mental da ação que permite planejar, resolver e autorregular a solução de situações-problemas dentro dos limites de uma generalização definida. Nesses termos, consegue transferir de forma criativa o que aprendeu para outras situações fora dos referidos limites utilizando-os como elementos do pensamento científico.

Essa interpretação da aprendizagem de conceitos teóricos na teoria de Galperin nos leva a dar a devida atenção ao papel da atividade orientadora e a orientação. Consequentemente, reduzir a compreensão de Galperin a respeito da aprendizagem à formação de novos conhecimentos e habilidades e / ou à sua atualização, é deixar fora dessa compreensão a essência da teoria, e confundir a essência com o fenômeno no sentido dialético.

\section{Caráter sistêmico da teoria de Galperin}

A teoria de Galperin pode ser considerada um sistema teórico (NÚÑEZ, 2009; OBUKHOVA, 2010). Isso exige certas determinações que, se desconsideradas, podem descaracterizar a compreensão da complexidade e das interações que se estabelecem entre os componentes do sistema, assim como das novas qualidades a este inerentes e não a suas partes ou subsistemas. Desejamos enfatizar que quando se enquadra a teoria num caráter de sistema, faz-se no sentido de uma visão dialética e complexa, como apresentam Reshetova (2004) e Núñez (2009).

O caráter sistêmico, dialético e complexo da teoria de Galperin nos leva a entender que, embora do ponto de vista metodológico se possam descrever cada um dos subsistemas, a qualidade da teoria como sistema não constitui uma somatória das propriedades de cada um deles, pois elas mudam nas relações dialéticas e diversas que estabelecem com o todo. Assim, como tampouco a teoria 
é apenas um ou outo de seus subsistemas. Um subsistema não pode ser isolado dos outros sem a sua descaracterização e da teoria.

Faz-se necessário também chamar a atenção que mal-entendidos e críticas que deles derivam revelam leituras fragmentadas fora de uma visão da teoria como um sistema, como tem apontado Gabay (2012). Nesse sentido, tentamos explicitar nossa interpretação da formação de conceitos teóricos na educação em Ciências, pautada no caráter de sistema da teoria de Galperin, na tentativa de defender a importância da compreensão dessa natureza da teoria.

\subsection{Subsistemas da teoria de Galperin}

De forma geral, quando discutimos a formação de conceitos teóricos na teoria de Galperin pode-se falar de três subsistemas integrados que a caracterizam como um sistema dialético e complexo em desenvolvimento. Eles são: o subsistema das condições que garantem a assimilação dos conceitos teóricos na correta realização das ações e no seu controle e regulação; o subsistema dos indicadores qualitativos que caracterizam níveis de desenvolvimento dos estudantes, resultado da aprendizagem; e o subsistema das etapas que garantem a formação da ação de orientação necessária e, consequentemente, dos conceitos teóricos (GALPERIN, 2001a). Devemos destacar que, em alguns de seus trabalhos, Galperin (1992) fala de quatro subsistemas, nos quais inclui o subsistema da motivação. Essa ideia foi desenvolvida posteriormente por Talizina (2009) como uma etapa da formação da orientação.

\subsubsection{Subsistema das condições}

Um dos subsistemas da teoria de Galperin é o das condições necessárias à aprendizagem dos novos conceitos, que tem sido o mais estudado, embora muitas vezes desconexo das etapas e dos indicadores qualitativos das ações nas quais se assimila e aplicam os conceitos teóricos.

Galperin (2001b) confere particular importância à ação de orientação que o estudante deve elaborar, na qual assimila e aplica o novo conceito teórico, o que 
permite o planejamento, a solução das situações-problemas, assim como o controle e regulação do processo de forma consciente. No entendimento de Galperin (2001b), todos os processos mentais são formas diferentes da atividade orientadora do sujeito face a uma dada situação-problema.

Baseado na teoria de Leontiev, Galperin (2001b) considera que a ação é formada por componentes estruturais e funcionais: os componentes estruturais da ação compreendem seus objetivos, os motivos, as operações, o processo e o sujeito que a realiza. Já seus os componentes funcionais compreendem a orientação, a execução e o controle. O primeiro que uma pessoa faz é orientar-se à procura de respostas em face a uma situação-problema que exige uma nova ação e um novo conhecimento ou uma ação ou conhecimentos que devem ser aplicados de uma nova maneira. A orientação é uma etapa inicial no processo de solução de novas tarefas e uma condição necessária para sua solução.

Segundo Galperín (2014), toda ação humana se realiza com base em algum tipo de orientação: "A representação antecipada da tarefa assim como o sistema de orientadores, que são necessários para sua solução, formam o plano da futura ação, a base de sua direção. A esse plano, nós denominamos de base orientadora da ação" (GALPERIN, 2014, p. 87).

O conceito de orientação na teoria de Galperin tem uma história. Foi desenvolvido intensamente não apenas por ele, mas também por alguns de seus discípulos, como explica Liders et al. (2012). Consequentemente, oferecemos nesta discussão nossa interpretação desta categoria central da teoria, tentando sempre ser coerentes com a essência das ideias formuladas e desenvolvidas por Galperin nos diferentes momentos que a formulou e reformulou, aperfeiçoando-a.

$\mathrm{Na}$ teoria de Galperin, a orientação que o estudante elabora sobre as ações que deve realizar para a assimilação do conteúdo de um conceito teórico tem um papel predominante no sistema que explica esse processo, não por serem os outros subsistemas indispensáveis, mas pela extensão de sua influência significativa que sobre eles exerce. Para aprender um novo conceito teórico, faz-se necessário partir de um determinado plano ou representações a seu respeito, o que Galperin denominou de orientação ou base orientadora da ação, que é o 
resultado de uma determinada atividade orientadora do sujeito na solução de situações-problemas. A orientação, nas palavras de Galperin (2001a), constitui a instância diretiva e, fundamentalmente, dela depende a qualidade da execução e da regulação do processo da aprendizagem.

Compreende-se, assim, que a orientação, ou Base Orientadora da Ação (BOA), constitui a representação que tem o sujeito da ação de orientação necessária ao conceito, na qual se inclui, e o conjunto de condições necessárias para a sua aplicação com sucesso (TALÍZINA, 2009). De acordo como Galperin (2001b), a Base Orientadora da Ação (BOA) articula a imagem da ação com a do meio no qual se realiza, num elemento estrutural único, possibilitando ao sujeito planejar, executar, regular e corrigir a ação necessária à solução de determinadas tarefas.

A base orientadora é um modelo da ação, um modelo para o pensamento, vinculada ao conceito de atividade. Não é estática, uma vez que, no próprio desenvolvimento da atividade, pode ser reconfigurada ou atualizada em função das novas experiências dos estudantes.

A BOA depende, dentre outros fatores, da natureza das tarefas ou das situações-problemas para as quais é necessária. Também depende das particularidades do conteúdo do conceito e do objetivo da ação, do caráter e da ordem das operações que entram na composição da ação, assim como das características dos recursos a serem utilizados na realização da ação. Sua estrutura é determinada pelas características da atividade a ser modelada, o que, na aprendizagem, funciona como atividade motivada (orientada por objetivos), investigativa e planejada sob controle voluntário (RESHETOVA, 2004).

Em seus estudos, Galperin (2001b) caracterizou três tipos de orientação, relacionadas com os tipos de aprendizagem que promovem. Esses tipos têm sido amplamente discutidos pelo autor, com destaque para a orientação denominada do tipo III, adequada à formação dos conceitos teóricos.

No terceiro tipo (BOA III), a aprendizagem se baseia no método de análise dos objetos e permite estabelecer a orientação necessária para resolver qualquer situação de uma classe determinada dentro dos limites de generalização estabelecidos. Pela análise, o estudante distingue as características e os parâmetros essenciais do 
material em estudo, ou seja, aqueles corretamente necessários para realizar a ação. Com isso, elabora uma invariante, ou esquema geral de orientação, que tem influência no seu desenvolvimento intelectual. Nas palavras de Galperin (2001b): "Nesse sentido, a aprendizagem constitui a forma de desenvolvimento intelectual." Esse tipo de orientação (BOA III) potencializa o desenvolvimento intelectual dos estudantes considerando sua natureza teórica, como afirma Núñez (2009).

A BOA III, como representação mental da ação na qual se inclui o conceito teórico e as condições de sua assimilação e aplicação, pode ter uma estrutura que geralmente deve levar em conta: a) a representação do produto final da ação de aplicação do conceito teórico na solução das situações-problemas; b) o modelo do objeto, que diz respeito ao conteúdo e estrutura lógica do conceito teórico; c) o modelo da ação que se refere ao sistema de ações e operações que permitem agir com o conceito na solução das tarefas para se chegar ao produto, segundo os objetivos; d) as condições necessárias à realização das ações com o conceito; e) os recursos necessários para a realização das ações; e f) as estratégias de controle, regulação e valoração das ações realizadas para a correção do processo, o que inclui a própria orientação quando necessário.

O conceito teórico, como produção das Ciências e seu conteúdo, incluído na definição e na estrutura geral da BOA III, geralmente não estão no campo da experiência dos estudantes. Por isso, como mostram diversas pesquisas, é difícil para os estudantes encontrar esse tipo de orientação por si mesmos. A tarefa do professor é ajudá-los a explicitar os esquemas de orientação que utilizam. No caso da BOA III, isso implicaria em um ato de criatividade. Da mesma forma, a BOA III orienta que o professor tem um papel essencial na orientação e na direção da aprendizagem. Não se trata do estudante descobrir por si só o essencial do conceito teórico, a ação adequada, assim como as condições necessárias que configuram a orientação tipo III, mas, sim, de elaborá-la com a ajuda e a colaboração do professor e dos colegas no contexto de dada Zona de Desenvolvimento Proximo (ZDP).

É bom destacar, por sua vez, que a BOA III é difícil de ser elaborada para atividades cuja estrutura operacional ainda não pode ser estabelecida ou não 
esteja internamente regulada. Ou mesmo para conceitos teóricos que não estão bem definidos e sejam claros num dado estágio do desenvolvimento do conhecimento científico. Essa dificuldade também se dá quando há atividades envolvendo tarefas com componentes heurísticos (RESHETOVA, 2004).

Da discussão anterior, sintetizamos que a orientação adequada à assimilação de conceitos teóricos nas aulas de ciencias é a BOA III, cuja formação se constitui no mecanismo psicológico da formação desse tipo de conceito. Destacamos essas ideias, porque são os tipos de conceitos que discutimos neste artigo.

\subsubsection{Subsistema dos indicadores qualitativos da ação}

Uma das críticas à teoria de Galperin questiona se é uma teoria sobre o desenvolvimento humano ou apenas explica processos da cognição humana (SIDNEVA, 2019). É certo que essa discussão deve ter como pano de fundo a compreensão que se tem do que é aprendizagem, do que é desenvolvimento integral e das relações que se estabelecem entre essas categorias da psicologia.

O contexto histórico no qual nasce e se desenvolvem as ideias de Galperin, como explicam Núñez e Oliveira (2015), mostra sua inserção numa sociedade preocupada não apenas com a instrução dos cidadãos, mas também com uma educação dirigida ao desenvolvimento pleno de suas personalidades, ou seja, para o desenvolvimento humano de forma integral e harmônica, para o qual a escola tem um papel essencial. Isso nos ajuda a não dissociar a teoria de Galperin de uma finalidade social e de uma prática pedagógica escolar para esses propósitos.

Importa comentar que Galperin (2001b), fundamentado em Vigotsky, considera que na sua teoria o papel do ensino é devidamente organizado como potencializador do desenvolvimento intelectual e, consequentemente, da personalidade dos estudantes. Ao considerar a orientação do terceiro tipo, assume que esta promove o desenvolvimento intelectual dos estudantes e que não se limita a uma dada aprendizagem. Embora Galperin não tenha desenvolvido uma teoria da personalidade, como explica Stepanova (2013), estruturou uma teoria 
psicológica geral (genética) que não pode ser separada da questão da psicologia da personalidade como parte integrante dessa psicologia geral.

Ao se pensar na teoria, é necessário reconhecer que aprendizagem dos conceitos teóricos tem como resultado algo que não pode ser reduzido a quantidades de conhecimentos e habilidades. Nesse sentido Galperin (2001b) estabelece um conjunto de indicadores da qualidade da ação de orientação a ser formada, que caracterizam os níveis das mudanças não apenas das aprendizagens, mas sim do desenvolvimenot inteletual que decorre dessas aprendizagens.

As mudanças qualitativas desses indicadores são resultado de modificações da estrutura das funções psicológicas superiores e do estabelecimento de novas relações entre as já formadas, o que, por sua vez, influencia o desenvolvimento intelectual (na capacidade de controlar e regular a própria aprendizagem), no sentido mais amplo, na personalidade do estudante. Esses indicadores caracterizam níveis de desenvolvimento intelectual dos estudantes e constituem um dos subsistemas da teoria.

Estabelecer a qualidade da formação dos conceitos teóricos é essencial na sua formação, uma vez que esta é um dos critérios para o planejamento e desenvolvimento das etapas de ensino e de aprendizagem nesse processo. Não obstante por vezes, isso é ignorado em muitos trabalhos de pesquisas e práticas de ensino que se declaram coerentes com a teoria de Galperin.

Galperin (2001a) pesquisou e caracterizou indicadores qualitativos das ações de orientação nos processos de formação de conceitos, diferenciando aqueles que podem ser formados direta e indiretamente como consequência de um ensino planejado, e de outros que se derivam desses e não são formados diretamente. Os indicadores do primeiro grupo denominou como primários e os do segundo, como secundários, não pela importância em relação à qualidade da ação, mas sim pela influência direta ou indireta do ensino sobre eles. Esses indicadores foram também estudados por outros autores, dentre eles Talizina (2009). Os indicadores primários são: a forma da ação, o grau de generalização, o caráter detalhado ou reduzido da ação, o grau de assimilação e o grau de independência. Esses são indicadores a serem levados em conta na formação da 
ação de orientação tipo III, necessária à assimilação dos conceitos teóricos como referência para a organização e desenvolvimento desse processo no contexto escolar. Como indicadores secundários incluímos o caráter racional, o grau de consciência e o grau de solidez.

$\mathrm{Na}$ opinião de Núñez et al. (2013), os indicadores qualitativos devem ser entendidos como um subsistema, no qual se integram diferentes elementos para ganhar dimensões que separados não possuem e expressam as transformações qualitativas no processo de formação dos conceitos teóricos.

Assim, os processos de ensino-aprendizagem, baseados na teoria de Galperin, se estruturam segundo um sistema de tarefas, que respondem à formação da BOA III, segundo os indicadores de qualidade desejados nos objetivos, os quais não devem ser excluídos desse processo de formação quando se aborda a teoria na sua natureza sistêmica.

As tarefas, ao modelizarem tipos específicos de atividades para a apropriação do conceito teórico dirigido por um objetivo, definem a interação entre os elementos didáticos pedagógico das ações de estudantes e professor. As tarefas de aprendizagem devem ser organizadas como um sistema complexo, como uma hipótese de progressão para o ensino que se dirige ao desenvolvimento dos estudantes.

Para Talízina (2009), as tarefas devem responder a duas exigências: a) considerar só o novo conceito que se deseja formar, uma vez que todos os outros conceitos e ações (ou tipos de atividades) que são necessárias para a sua assimilação devem ter sido anteriormente aprendidos; b) a forma de apresentação das tarefas deve corresponder à etapa de assimilação da orientação. Em cada etapa do processo de formação da orientação, as tarefas se estruturam segundo os indicadores qualitativos da atividade.

A formação da orientação tipo III, que tem como finalidade a assimilação do conceito teórico segundo os indicadores de qualidade, requer as tarefas que destacamos a seguir. Para formar a ação de orientação, as tarefas apresentadas devem ser resolvidas de acordo com a etapa de assimilação, ou seja, no plano externo com a ajuda do esquema da BOA III, no plano da linguagem externa (sem apoio externo) e no plano mental. Já a formação do grau de generalização é 
realizada pela apresentação de vários tipos de tarefas: objetiva, lógica, psicológica e do tipo direta e inversa, para os diferentes casos em que é possível trabalhar de acordo com a orientação geral, diferenciando-os dos casos em que não é possível resolver as tarefas de acordo com a BOA III. Também inclui tarefas para transferir o aprendizado para novas situações que exige a reelaboração da orientação tipo III para um novo referente à situação particular. Esse tipo de tarefa implica numa dada atividade criativa dos estudantes.

A maneira de trabalhar o grau de independência é oferecer aos alunos diferentes níveis de ajuda, quando necessário, a fim de avançar em direção à independência cognitiva na resolução de tarefas À medida que o processo avança pelas etapas de assimilação, o aluno não precisa mais de ajuda externa, até poder realizar a atividade de forma independente.

Para o grau de detalhamento, utilizam-se tarefas que garantam a redução da orientação inicialmente explicitada de forma detalhada no EBOCA para representações ou explicações orais ou escritas menos detalhadas, na medida em que se assimilam os elementos estruturais da orientação. $O$ caráter assimilado da ação se forma pela solução de tarefas nas quais se graduam seus níveis maiores ou menores de dificuldades.

Essas tarefas formam um sistema no qual se integram umas com as outras para a formação da qualidade da ação de orientação como um todo. Embora os indicadores secundários de qualidade da ação sejam dependentes dos primários, destacamos algumas observações que consideramos pertinentes em relação a esses indicadores secundários.

O grau de consciência é formado de duas maneiras: primeiro, o aluno toma consciência da lógica da estrutura da atividade que realiza, não apenas resolvendo reflexivamente a tarefa de acordo com estratégias metacognitivas, mas também segundo a maneira de apresentar a tarefa, o que requer uma reflexão consciente sobre as formas de resolver os problemas. Em segundo lugar, pede-se ao aluno que explique e / ou discuta em voz alta, ou por escrito, as ações que desenvolve, de tal maneira que trabalhe na tradução da lógica das ações externas para a lógica dos conceitos ou formulações verbais. 
O caráter racional da ação resulta do uso de tarefas que demandam dos estudantes diferenciar, de forma consciente, o essencial do não essencial da situação problema em relação ao conteúdo do conceito teórico que assimilam, o que depende do grau de generalização e do caráter detalhado da ação de orientação.

Já a respeito da solidez da ação, é preciso prestar a devida atenção às tarefas que permitam o transito por suas etapas, com destaque para o elevado nível de generalização.

\subsubsection{Subsistema das etapas de assimilação dos conceitos}

O terceiro dos subsistemas da teoria corresponde ao das etapas de formação do conceito teórico ou das ações, baseado, dentre outros, no princípio de internalização desenvolvidos por Vigotsky e Leontiev. Ressalta-se que é na sua aplicação que as ideias de Galperin têm sido objeto de críticas (NÚÑ̃Z, 2009).

É possível que as mais conhecidas sejam as de Rubinstein (1986). Segundo esse autor, é incorreto pensar que toda ação mental tenha seu protótipo em uma dada ação externa, material, ou mesmo que essa ação externa seja um prérequisito para a formação da ação mental. Da mesma forma, Rubinstein (1986) atribue a Galperin a ideia da internalização como reprodução da ação material, externa, como sua cópia no plano mental, o que tem sido refutado por vários autores como Sidneva (20019), Núñez (2009), Leontiev (2005), que argumentam a respeito da falta de compreensão desses críticos do caráter de sistema e dos fundamentos filosóficos da teoria de Galperin.

Ao pensar a formação dos conceitos científicos segundo a ZDP, Galperin (2001b) considerou como insuficiente nas suas pesquisas levar em conta apenas as diferenças dos índices das possibilidades do estudante para resolver uma tarefa sozinho ou com a ajuda de um colega mais experiente ou do professor. Ele justificou ser importante entender os mecanismos de como se passa da atividade colaborativa à independência cognoscitiva, ou seja, como se dá a passagem do plano interpsicológico (externo) da atividade psíquica para o plano mental com o processo de internalização na formação de novos conceitos científicos. 
Galperin (2001a) retoma a ideia da internalização das funções psicológicas superiores de Vigotsky e a leva de seu significado inicial para uma compreensão do processo que pode explicar a formação das ações mentais e dos conceitos, fornecendo um novo conteúdo ao significado da internalização da teoria de Vigotsky.

É importante destacar que Galperin desenvolve e expande as ideias de internalização de Vigotsky e de Leontiev no mecanismo da formação das ações mentais e dos conceitos para o estudo da consciência, explicado pelas etapas que tratam esse processo, não como uma ação mecânica, de base empirista, mas, sim, na dialética das contradições que se produzem nos processos de internalização e externalização da atividade humana. Toda atividade externa do homem se relaciona com componentes psíquicos pelos quais se regula, significa e se objetiva.

Seguindo as ideias de Leontiev (2005), o processo de internalização não a transposição de uma função do exterior para o interior (a psique humana), mas sim o processo de construção das estruturas internas (mentais) da consciência. Dessa forma, como alerta o autor, a palavra "internalização" deve ser considerada como uma metáfora que descreve o desenvolvimento das funções psicológicas superiores.

Interpretamos a formação dos conceitos teóricos na teoria de Galperin como um processo de internalização da orientação tipo III, na qual se inclui o conceito. Inicialmente, a orientação se realiza com a ajuda externa materializada no EBOCA, passando para a forma com ajuda da linguagem externa, oral e / ou escrita, e, no final, para a forma plenamente mental, na qual não se precisam dos mediadores das etapas precedentes para a solução das tarefas com sucesso. Isso leva a mudanças nas formas de compreender e explicar o mundo físico, o que por sua vez influencia na reconstrução do pensamento científico do estudante.

Como assinala Sidneva (2019), cosideramos necessário destacar a crítica à teoria de Galperin relativa à internalização e a natureza psíquica e subjetiva da orientação. A orientação do sujeito é sempre um processo psíquico que não pode existir fora de sua cabeça, dessa forma, não tem sentido falar de uma ação de orientação externa totalmente materializada (fora do sujeito, de forma absoluta e material). Acreditamos que Galperin, ao tratar das formas da ação de orientação, se refere a como o interno se relaciona com o externo de forma dialética e sobre 
quais apoios e ferramentas mediadoras o sujeito utiliza na sua orientação que permite a assimilação dos conceitos, que são indicadores de níveis de domínio no seu processo de internalização / externalização.

Uma orientação como ação materializada é sempre uma ação mental, mas que precisa do EBOCA como apoio externo mediador para ser realizada. O mesmo acontece com a ação de orientação na forma da linguagem externa. Já a orientação mental se diferencia das outras pelas possibilidades do sujeito poder orientar-se na solução das tarefas e na sua conduta sem mediadores como a linguagem externa ou suportes externos materializados.

Segundo os indicadores de qualidade definidos nos objetivos, o processo de elaboração de uma nova BOA III, necessária à formação do novo conceito teórico, deve transitar pelas etapas da teoria de Galperin, em dependência dos níveis de domínio inicial da orientação a ser formada. Por isso, a importância de um diagnóstico adequado dos referidos níveis da orientação de que dispõe o estudante, o que deve permitir ao professor caracterizar os elementos estruturais dessa orientação na organização do processo.

A formação da BOA III necessária à assimilação do novo conceito teórico, transita, como foi dito, pelas etapas detalhadas por Galperin (2001b) em dependência dos níveis iniciais de seu desenvolvimento. Principalmente, porque os estudantes não tem familiaridade com esse tipo de orientação e pelas exigências que se impõe no processo de sua elaboração.

Entendemos que a motivação inicial pode ser criada como parte do momento do diagnóstico dos níveis de desenvolvimento da orientação, baseadas em contradições dialéticas que devem provocar necessidades de aprender e motivos para a busca de soluções, que serão realizadas na etapa de elaboração da orientação.

Na elaboração da BOA III, necessária à formação do conceito teórico, face a uma situação-problema típica (com potencial de abarcar todos os casos dentro dos limites de generalização estabelecidos), os estudantes, de forma colaborativa e sob a orientação do professor, realizam determinadas atividades de pesquisaorientação para encontrar formas que possibilitem a definição do novo conceito, ações adequadas e condições nas quais podem aplicar o conceito teórico. 
Sendo assim, os estudantes devem refletir, tomar consciência do conteúdo do conceito, de sua estrutura lógica, das ações que devem realizar, nas quais se incluem as operações necessárias, estabelecendo as condições que permitem uma orientação do tipo III para dar sentido ao processo de solução da tarefa que representa uma variante de um grupo mais geral de situações-problemas. É uma etapa para a compreensão dos problemas e suas possíveis soluções que devem aprender como estratégia para a formação do conceito teórico.

A elaboração (ou reelaboração) da orientação dos estudantes (como sujeitos da atividade investigativa de orientação) pode ser realizada como um processo de negociação dos sentidos por eles explicitados no diagnóstico inicial e no significado da BOA III estabelecida pelo professor e necessariamente adequada ao conhecimento científico da disciplina. A orientação necessária à formação do conceito deve permitir a solução não de um caso particular, mas de um grupo de situações do mesmo tipo (NUÑEZ, 2009).

A BOA III, elaborada pelos estudantes nessa etapa, deve ser representada de forma gráfica, como um esquema, denominada por Galperin (1992) de Esquema da Base Orientadora Completa da Ação (EBOCA), o qual se institui como uma ferramenta cognitiva externa mediadora na internalização da orientação para a solução das tarefas na etapa materializada. É importante destacar a necessidade de promover diversas formas de representar o EBOCA, como diagramas, notas, mapas ou outros esquemas que respeitem as preferências e possibilidades dos estudantes. O necessário nesse caso é compartilhar o conteúdo da BOA III, negociada com a referência definida na disciplina.

O EBOCA, enquanto ferramenta mediadora da atividade na etapa materializada da orientação, possibilitará aos estudantes compreender as situações-problemas, planejar e realizar as soluções de forma regulada, sob controle voluntário, consciente, valorando o processo e fazendo as correções necessárias nessa etapa, o que se faz extensivo para as próximas etapas, mas de forma diferente em relação à forma de orientação.

Nessa etapa, os estudantes, apoiados no EBOCA de forma colaborativa e comunicando-se de forma oral e / ou escrita, resolvem diversas tarefas de acordo 
com as exigências dos indicadores para essa etapa e realizam o controle do processo de solução das tarefas. O EBOCA, inicialmente detalhado em relação ao conteúdo do conceito e aos outros aspectos estruturais, vai se reduzindo e, dessa forma, na medida que seja necessário, os estudantes podem reelaborá-lo sem novamente explicitar os detalhes aos quais passaram a ter domínio.

$\mathrm{Na}$ opinião de Galperin (2001b), essa é uma etapa necessária quando o estudante não tem um domínio inicial adequado da orientação a ser formada, o que também corresponde às exigências da compreensão e objetivação da orientação. Quando o estudante não precisa mais apoiar-se no EBOCA, pode passar à etapa da orientação com base nos recursos da linguagem externa.

$\mathrm{Na}$ etapa da linguagem externa, as tarefas se apresentam e se resolvem segundo as possibilidades que oferecem as linguagens oral e escrita. A orientação, por sua vez, se realiza também na forma dessas linguagens, tendo agora a função essencial de comunicação. A linguagem é essencialmente um meio de reflexão consciente do processo. As tarefas utilizadas se referem ao mesmo conteúdo da orientação na qual se inclui o conceito teórico, variando a forma e atendendo aos indicadores qualitativos estabelecidos. O estudante pode passar para a próxima etapa quando as evidências no planejamento, na execução das ações, no uso do conceito teórico e do controle na solução das tarefas mostram suas possibilidades de não precisar operar nessa forma. Nesse momento, a orientação passa a ser um ato do pensamento, ainda que com determinados níveis de detalhamento.

$\mathrm{Na}$ etapa mental, a orientação III é um ato do pensamento de cada estudante e se apresenta integrada a suas estruturas cognitivas, parte do pensamento científico, possibilitando pensar usando o conceito teórico e em correspondência com os indicadores qualitativos de desenvolvimento intelectual definidos nos objetivos.

Quando a nova orientação tipo III, que inclui o conceito teórico, é internalizada, o estudante dele se apropriou e pode pensar dentro de uma rede conceitual, diferenciando quais situações-problemas podem e quais não podem ser resolvidas com esse domínio conceitual, com autonomia intelectual. Pode, dessa forma, face a situações-problemas que estejam dento dos limites de generalização da 
BOA III planejar e realizar a sua solução, aplicando o conceito de forma produtiva, e realizar o controle e autorregulação consciente do processo e com autonomia.

$\mathrm{Na}$ teoria de Galperin, a formação de conceitos teóricos deve levar em conta que os estudantes têm diversas experiências e vivências, conhecimentos prévios e motivações a ser consideradas como elementos do planejamento desse processo. Isso não significa um ensino individualizado, pois os estudantes também compartilham aspectos do conteúdo da orientação a ser formada, mas é muito importante respeitar a dialética do singular e do geral, das subjetividades e do grupo como um todo. O planejamento do ensino e a aprendizagem dos estudantes não responde a roteiros homogenizadores que desrespeitem essa dialética.

O processo de internalização da ação de orientação tipo III como mecanismo psicológico da formação de conceitos teóricos nas aulas de Ciências se descreve nas etapas da teoria de Galperin. Esse não é um processo linear, mas um ciclo no formato de uma espiral das aprendizagens dos estudantes. Nessa espiral, se interligam as diferentes etapas como negações dialéticas, não num círculo, e sim numa forma que entrelaça as diferentes etapas marcadas pelas contradições e conflitos, chegando a um plano superior, indicador do desenvolvimento humano.

\section{Conclusões}

A teoria de Galperin oferece uma dentre outras maneiras de se pensar as condições para a formação do pensamento científico nos estudantes a partir da formação de conceitos teóricos da disciplina científica num ensino que não se separa da aprendizagem, e que se dirige para o desenvolvimento integral dos estudantes, permitindo aos pesquisadores e professores uma referência psicopedagógica para sua atividade profissional. Nesse contexto, constatamos um determinado avanço no interesse de pesquisas sobre essa temática no Brasil.

Embora haja avanço, identificamos interpretações da teoria que, por vezes (de forma não intecional), reforçam críticas tradicionais às ideias de Galperin, as quais esse artigo procurou fornecer determinados pontos de vistas considerando nossas interpretações e experiências com o referencial galperiano. Essas reflexões, 
apresentadas são, por sua vez, uma forma de chamar a atenção para questões necessárias ao debate teórico-metodológico de pesquisas sob esse referencial.

Determinadas críticas à teoria de Galperin se associam a um mal-entendido do programa de ensino que deriva dos fundamentos da teoria ao desconsiderar o seu caráter dialético e complexo. Assim, valoramos a importância de um debate sobre os tipos de conceitos, neste caso, os teóricos, estruturantes do conteúdo de disciplinas da educação científica dos estudantes da educação básica. Sustentamos ser a formação da BOA III o mecanismo psicológico pelo qual se elaboram e se mobilizam esses conceitos, de forma a potencializar o desenvolvimento do pensamento científico dos estudantes e o desenvolvimento integral de suas personalidades, o que exige de uma visão sistêmica, complexa e totalizante da teoria.

É um erro, a nosso modo de ver, associar a teoria de Galperin à ideia de tecnologia educacional ou a um algoritmo como uma sequência de momentos que devem ser seguidos por todos os estudantes sob um planejamento didático rígido, que conduz aos mesmos resultados e priva os estudantes de suas subjetividades e criatividade. A própria teoria tem o compromisso com o desenvolvimento da personalidade do estudante, o que implica necessariamente a subjetividade e uma atitude criativa como uma das finalidades da boa educação.

Por fim, enfatizamos que os pontos de vistas defendidos neste artigo são uma interpretação do processo de formação dos conceitos teóricos, que possibilita responder algumas críticas feitas à teoria, assim como alguns equívocos que podem ser encontrados em estudos que assumem um compromisso com a teoria e, de certa forma, não refletem seus fundamentos essenciais.

\section{Referências}

GABAY, T.V. Galperin's Scientific Ideas and Their Development within Modern Activity Theory of Learning. Cultural-Historical Psychology, v. 8, n. 4, p. 28-37, 2012.

GALPERIN, P. Ya Sobre la formación de los conceptos y de las acciones mentales. In: ROJAS, L. Q. La formación de las funciones psicológicas durante eldesarrollo del niño. Tlaxcala: Editora Universidad Autónoma de Tlaxcala, 2001a. p. 27-40. 
GALPERIN, P. Ya Stage-by-Stage Formation as a Method of Psychological Investigation. Journal of Russian and East European Psychology, v. 4, n. 30, p.60-80, Jun. 1992. https://doi.org/10.2753/rpo1061-0405300460

GALPERIN, P. Ya. The role of orientation in thought. Soviet Psychology, Philadelphia, v. 18, n. 2, p. 84-99, 2014.

GALPERIN, P. Ya. Tipos de orientación y tipos de formación de acciones y de los conceptos. In: ROJAS, L. Q. La formación de las funciones psicológicas durante el desarrollo del niño. Tlaxcala: Editora Universidad Autónoma de Tlaxcala, 2001b. p. 41-56.

GALPERIN, P. Ya. Organization of mind activity and effectiveness of learning. Soviet Psychology, Philadelphia, v. 27, n. 3, p. 65-82, 1989.

LEONTIEV, A. D. Aproximación a la teoria de la actividad: Vigotsky en el presente. Ecleta, v.3. n. 9. p. 29-39, 2005.

LEONTIEV, A. N. Actividad, Consciencia, Personalidad. La Habana: Editorial Pueblo y Educación, 1992.

LIDERS A.G. et al. Evolution of Concepts of Orientation and Orienting Activity in Galperin's Theory. Cultural-Historical Psychology, v. 8, n. 4, p. 13-27, 2012.

NÚÑEZ, I, B.; RAMALHO, B. L. A teoria da formação planejada das ações mentais e dos conceitos de P. Ya. Galperin: contribuições para a didática desenvolvimental. Obutchenie. Revista de Didática e Psicologia Pedagógica, v. 1, n. 1, p. 1-29, jan./jul. 2017. https://doi.org/10.14393/obv1n1a2017-4

NÚÑEZ, I. B, et al. Os indicadores qualitivos da ação e as tarefas de aprendizagem; reflexões teóricas e didáticas na teoria de P. Ya. Galperin. Revista Amazônica. Ano 6, v. XI, número 2, Jul-Dez, p. 388-415, 2013.

NÚÑEZ, I. B. Vygotsky, Leontiev, Galperin. Formação de Conceitos e princípios Didáticos. Brasília: Liber Livro, 2009.

NÚÑEZ, I. B.; OLIVEIRA, M. V. de F. P. Ya. Galperin: vida e obra do criador da teoria da formação por etapas das ações mentais e dos conceitos. In: LONGAREZI, Andréa Maturano. PUENTES, Roberto Valdés (Orgs.). Ensino Desenvolvimental II: vida, pensamento e obra dos principais representantes russos. Uberlândia: Edufu, 2015. p. 283-314. https://doi.org/10.14393/edufu-978-85-7078-464-3

OBUKHOVA L.F. Galperin Theory. Establishment of a New Branch in Psychology. Cultural-Historical Psychology, v. 6, n. 4, p. 4-10. 2010. 
RESHETOVA, Z. A. The organization of the activity of learning and the student's development. Russian Education and Society, Moscow, v. 46, n. 9, p. 46-62, Sept. 2004. https://doi.org/10.1080/10609393.2004.11056909

RUBINSTEIN,S. L. El problema de las capacidades y las cuestiones relativas a la psicologia general. In: ILIASOV, I. I; LIAUDIS, V. Y. Antologia de la Psicologia Pedagógica y de las edades. La Habana: Editorial Pueblo y Educación. 1986. p. 54-67.

SIDNEVA A.N. Basic Objections to the Theory of Stage-By-Stage Formation of Mental Actions and Concepts. Cultural-Historical Psychology, v. 15, n. 3, p. 2231. 2019. https://doi.org/10.17759/chp.2019150303

STEPANOVA M.A. The Problem of Personality in Peter Ya. Galperin's Scientific Legacy. Cultural-Historical Psychology, v. 9, n. 4, p. 101-110. 2013.

TALÍZINA, N. F. La teoría de la actividad aplicada a la enseñanza. Editorial de la Benemérita Universidad Autónoma de Puebla. Puebla: México, 2009.

VIGOTSKY, L. S. La historia del desarrollo de las funciones psíquicas superiores. La Habana: Editorial Científico Técnico, 1987. 